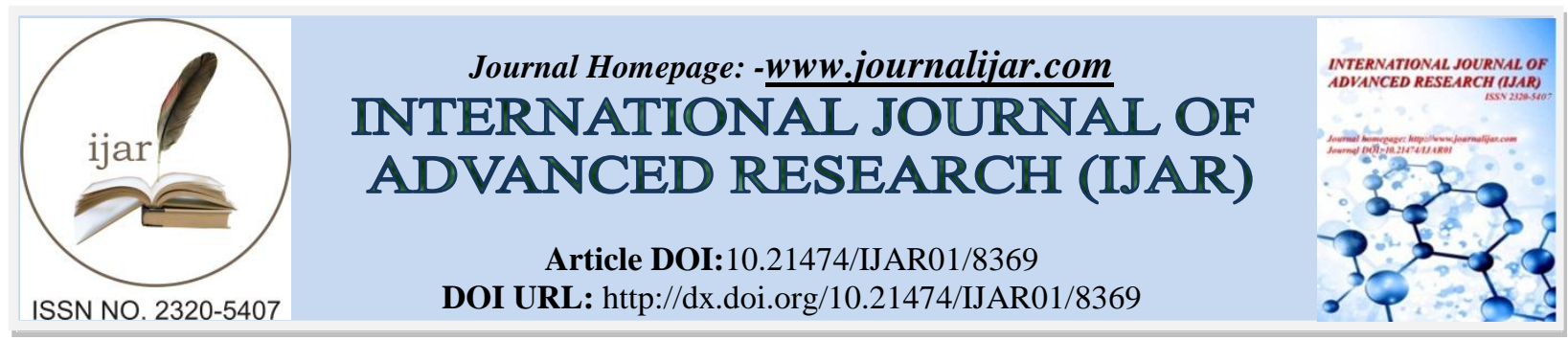

RESEARCH ARTICLE

\title{
MYOPATHYAS AN UNUSUAL PRESENTATION OF OSTEOMALASIA IN ADOLESCENCE, CASE REPORT.
}

\begin{abstract}
Alaa QasimAlawadi.
FIMC ofpediatrics, Karbala Teaching Hospitalfor children, Karbala , Iraq .

\section{Manuscript Info}

Manuscript History

Received: 10 November 2018

Final Accepted: 12 December 2018

Published: January 2019

Key words:-

Proximal myopathy,osteomalacia in adolescence, vitamin D deficiency.

\section{Abstract}

Reporting an adolescent patient with osteomalacia presented initially with complete inability to walk and clinicalfeatures consistent with proximal myopathy which is one of the uncommon presentation for osteomalasia and vitamin D deficiency.

Afterexcluding other causes leading to myopathy by clinical,laboratory ,graphical and imaging methods and confirming the diagnosis of osteomalacia by lab. And radiological methods . Remarkable improvement of the myopathy and other signs and symptoms of vitamin $\mathrm{D}$ deficiency after starting the treatment with vitamin $\mathrm{D}$ and calciumsuppliment was noted.

This report illustrates the importance of consideringosteomalaciaas a possible and treatable cause of proximal myopathy in adolescents and young adults .
\end{abstract}

Copy Right, IJAR, 2017,. All rights reserved.

\section{Introduction:-}

Osteomalacia is a disorder of decreased mineralization of newly formed osteoid at sites of bone turnover, whereas rickets is a disorder of defective mineralization of cartilage in the epiphyseal growth plates of children. Osteomalacia and rickets can occur together in children (open growth plates), but only osteomalacia occurs in adults (fused growth plates). Several different disorders cause osteomalacia[1].Populations at risk include the homebound who have little sun exposure and insufficient dietary calcium and vitamin D, patients with malabsorption related to gastrointestinal bypass surgery or celiac disease, and women who wear traditional veils or dresses which prevent sun exposure $[2,3]$.

Hereditary forms of vitamin D deficiency and resistance, which are identified in childhood, are associated with osteomalacia in adults, but these disorders are less common

In developing countries,vitamin D deficiency rickets is still considered as a major community health problem in infants and children causing, whileOsteomalacia due tovitamin D deficiencyis reported with increasing frequencyamong adolescents [2-3].

Proximal myopathy occur in association with several muscle diseases. However, myopathy associated Vitamin D deficiency is an unusual cause of myopathy [4-6]. This causative association can easily be overlooked although the condition is readily treatable.

Corresponding Author:-Alaa QasimAlawadi.

Address:-FIMC ofpediatrics, Karbala Teaching Hospitalfor children, Karbala , Iraq . 
In this case report, we present our experience with an adolescentpatients with osteomalacia who presented with proximal myopathy.thepatient responded very well to vitamin Dtherapy and calcium supplement.

\section{Methods \& Results:-}

A 13years old female presented to us in the general pediatric ward, in a wheel chair, in able to walk, complaining of pain in her extremities and back with a history of progressive weakness, fatigability, lethargyand difficultyin climbing stairs and standing up from sitting position. Her condition worsened in the last 6 months.

Her diet consist no milk ormilk product intake. She reported minimal sun exposure in her dailylife. She had no symptoms to suggest malabsorption, liverand renal diseases no history of fracture.

On examination the patient was fully conscious, depressed looking, well nourished, white skin(Caucasian), alert girl withno dysmorphic features.Stablevital signs. Growth assessment indicated that her weight was $50 \mathrm{~kg}$ at $50^{\text {th }}$ centile, and her height was $147 \mathrm{~cm}$ at 25 th centile. she hadcarpopedal spasm (noted when we took her blood pr.). Cardiovascular,chest and abdomen examination wasnormal. Examinationof thecentral nervous system revealed cranial nerves normal. Unstable gait, unable to rise from squatting position withproximal muscle weakness which was demonstratedby failure to overcome mild resistance at lowerlimbs and by moderate resistance at upper limbs. Therewas no evidence of muscular atrophy or tenderness eitherin the upper or lower limbs. Deep tendon reflexes andsensation were intact.Laboratory investigations showed normal complete bloodcount (CBC), Random blood sugar (RBS) $126 \mathrm{mg} / \mathrm{dl}$,serum calcium was $4.2 \mathrm{mg} / \mathrm{dl}$,normal serum phosphate, normal other electrolytes including serum potassium level.Alkaline phosphatase $447.4 \mathrm{U} / \mathrm{L}(\mathrm{N}=40$ 150), normal liver function, renal function\& blood gas, CPK $53.26 \mathrm{u} / \mathrm{dl}(\mathrm{N}=29$ -

200),normal celiac screening and thyroid function, and.iPTH was $515.7 \mathrm{pg} / \mathrm{mg}(\mathrm{N}=15-68), 25$ hydroxyvitamin $\mathrm{D}$ was very low $1.6 \mathrm{ng} / \mathrm{ml}(\mathrm{N}=30-40)$. X-ray of pelvis AP showed severe generalized osteopenia with no fractures. EMG was normal .DEXA scan (bone density measuring scan) not available in our hospital

calcium was given to correct the acute symptoms \&signs of hypocalcaemia As osteomalaciawas Confirmed biochemically and radiologically .patientreceivedalphacalcidiol one microgramtwice daily $(0.05$ microgram $/ \mathrm{kg})$ calcium intake of at least $1000 \mathrm{mg}$ per day).all patients should maintain a calcium intake of in the range of 1000 to1500 for 2 months, since inadequate intake of calcium may contribute to the development of osteomalacia [18-19].

The patient myopathy improved remarkably with in the first 4 days \&responded very well totreatment in terms of feeling of well-being,mobility,gait,and muscle power .she was discharge after a week of hospitalization to complete the line of therapy at home with instructions regarding diet .sport,and sun exposure. After 2 months of treatment symptoms and sign of myopathy recovered completely and symptoms of fatigue ,depression disappear ,the vitamin D level with in normal range.

\section{Discussion:-}

There is a growing prevalence of vitamin D deficiency in many countries, which when severe (25-hydroxyvitamin D $<10 \mathrm{ng} / \mathrm{mL}$ [25 nmol/L]) and prolonged, results in:hypocalcemia, secondary hyperparathyroidism, secondary hypophosphatemia, and osteomalacia [8].

The main cause of osteomalasiaworldwide are vitamin D deficiency.thewell known causes is low intake and limited sun exposure[9]., gastrointestinal diseases as malabsorption,. Other causes include Vitamin D resistance , hereditary or acquired disorders of phosphate wasting, type 2 renal tubular acidosis, and excessive exposure to inhibitors of bone mineralization (eg, aluminum toxicity, endemic fluorosis)

no study showing the prevalence of osteomalasia inKarbala nor in Iraq was found .but studies from Saudi Arabia[6-7] showed that vitamin D level tend to below among the general population especially children and females . The conservative environment in the holy city of Karbala is so much similar to that of Saudi Arabia.regardingwomen who wear traditional veils or dresses 
(thick black rather sacred clothing) .one study done in Department of Pediatrics, College of Medicine and King Khalid University Hospital, King Saud University, Riyadh [6],got to the same conclusion of our study .in the study mentioned they had 3 cases which were all females which had myopathy as a presenting feature of thereosteomalasia. This out weightthe explanationof the clothing habits..

Osteomalacia may be asymptomatic and present radiologically as osteopenia. It can also produce characteristic symptoms, independently of the etiology, including diffuse bone pain, polyarthralgias, muscle weakness, and difficulty walking [10-12]. Few previous studies reported the association of myopathy with vitamin D deficiency . In a report[13], 17 patients with osteomalacia on bone biopsy, the following findings were observed: (Bone pain and muscle weakness in 84 percent ,Bone tenderness in 84 percent,Fracture in 76 percent.Difficulty walking and waddling gait in 24 percent .This diversity in the presentationof osteomalasia and limitated number of studies addressing the problem may explain the lack of attention of doctors to osteomalasia as a cause of myopathy in practice.famous academic books didn't mention the myopathy as a finding in osteomalasia[22].

The actual scientific explanation of myopathy related to osteomalasia have been poorly elicited ,Some studies implicate it to direct effect of vit .D on skeletal muscles,others to the effect of secondary hyperparathyroidism causing atrophy in muscle fibers type $2,[9,14,15]$

No study was found regarding theimprovement timeneeded ,thehealing of the myopathy- in our patient - was remarkable, started to be obvious within the first 4 daysof starting the treatment, patient was walking on discharge,(10 days later) .follow up 1 month later, still on therapy, normal gait and muscle power, can climb stairs, vit. D reading was $19.3 \mathrm{ng} / \mathrm{dl}$ and two months later $22 \mathrm{ng} / \mathrm{dl}$ her mother then reported her daughter less depressed more active participating in sports .she was changed to vit.D3 50u/wk to maintain the results and prevent recurrence.

Healing of osteomalaciaand bone densityhealing may take many months to a year and varies with the degree and duration of the deficiencyin one study bone density may improve within three to six months but it starts by when there are increases in urinary calcium excretion[17]. This will be reported with future follow up of the patient.

DEXA scan not available in our governmental hospitals in karbala.to confirm osteomalacia.Several studies have demonstrated markedly reduced spine, hip, and forearm bone density in patients with osteomalacia related to vitamin D deficiency [20 -21].

It is not a common clinical practice to consider osteomalasia and vitamin D deficiency in the differential diagnosis of muscle weakness and proximal myopathey, Normal CPK in the presence of clinical evidence of myopathy may draw the attention to the possibility of osteomalasia\& vitamin D deficiency as the underlying cause.

\title{
Conclusion:-
}

proximal myopathy is an uncommon butimportant feature of osteomalacia in adolescence . in this study we highlight the importance of considering osteomalacia as one of the differential diagnosis of anypatient who presents with proximal muscle weakness.

\author{
Abbreviations:- \\ PTHParathyroid Hormone \\ CPKCreatinine Phosphokinase \\ ALP Alkaline Phosphatase \\ Vit.D Vitamin D \\ EMGElectromyogram \\ DEXADual -Energy X-ray Absorptiometry
}




\section{References:-}

1. CJ Menkes, MD. Osteomalasia up to datefile://F:/UpToDate19.3/UpToDate19.3/contents/mobipreview.htm?37/34/38446\#H3169360

2. Al-Shoha A, Qiu S, Palnitkar S, Rao DS. Osteomalacia with bone marrow fibrosis due to severe vitamin D deficiency after a gastrointestinal bypass operation for severe obesity. EndocrPract 2009; 15:528.

3. Kennel KA, Drake MT, Hurley DL. Vitamin D deficiency in adults: when to test and how to treat. Mayo ClinProc 2010; 85:752.

4. Pfeifer M, Begerow B, Minne HW. Vitamin D and muscle function. Osteoporosis Int 2002; 13: 187-94

5. Glerup H, Mikkelsen K, Poulsen L, et al. Hypovitaminosis D myopathy without biochemical signs of osteomalacicbone involvement. Calcif Tissue Int 2000; 66: 419-424.

6. Hessah M. AL-Otaibi, Nasir A.M AL-Jurayyan, Sarar Mohamed, Mustafa A. M. SalihOsteomalacia in adolescents presenting as proximal myopathy

7. Department of Pediatrics, College of Medicine and King Khalid University Hospital, King Saud University, Riyadh, Saudi Arabia.CurrPediatr Res 2012; 16 (1): 57-60

8. Abdullah MA, Salhi HS, Bakry LA et al .adolescent rickets in Saudi Arabia: a rich and sunny country. J PediatrEndocrinolMetab 2002; 15: 1017-1025

9. shwell M, Stone EM, Stolte H, et al. UK Food Standards Agency Workshop Report: an investigation of the relative contributions of diet and sunlight to vitamin D status. Br J Nutr 2010; 104:603

10. Glerup H, Mikkelsen K, Poulsen L, et al. Hypovitaminosis D myopathy without biochemical signs of osteomalacic bone involvement. Calcif Tissue Int 2000; 66: 419-424

11. Lips, P, van Schoor, NM, Bravenboer, N. Vitamin D-related disorders. In: 'Primer on the metabolic bone diseases and disorders of mineral metabolism" Seventh edition, Rosen, CJ (Eds), American Society of Bone and Mineral Research, 2008. p.329.

12. Gifre L, Peris P, Monegal A, et al. Osteomalaciarevisited : a report on 28 cases. ClinRheumatol 2011; $30: 639$.

13. Bhan A, Rao AD, Rao DS. Osteomalacia as a result of vitamin D deficiency. EndocrinolMetabClin North Am 2010; 39:321.

14. Basha B, Rao DS, Han ZH, Parfitt AM. Osteomalacia due to vitamin D depletion: a neglected consequence of intestinal malabsorption. Am J Med 2000; 108:296.

15. Ceglia L. Vitamin D and skeletal muscle tissue andfunction, Molecular Aspects of medicine 2008; 29:407-414.

16. Russell JA, Ostemalacic Myopathy. Muscle Nerve 1994; 17: 578-580

17. Bhan A., Rao AD, Rao AS. Osteomalacia as a result of vitamin D deficiency. Endocrinology and Metabolismclinic 2010; 39 (2): 321-331

18. Allen SC, Raut S. Biochemical recovery time scales in elderly patients with osteomalacia. J R Soc Med 2004; 97:527

19. Thacher TD, Fischer PR, Pettifor JM, et al. A comparison of calcium, vitamin D, or both for nutritional rickets in Nigerian children. N Engl J Med 1999; 341:563.

20. Bishop N. Rickets today--children still need milk and sunshine. N Engl J Med 1999; 341:602.Basha B, Rao DS, Han ZH, Parfitt AM. Osteomalacia due to vitamin D depletion: a neglected consequence of intestinal malabsorption. Am J Med 2000; 108:296.

21. Bhambri R, Naik V, Malhotra N, et al. Changes in bone mineral density following treatment of osteomalacia. J ClinDensitom 2006; 9:120.

22. Robert M. Kliegman, MD. Nelson text book of pediatrics 20 editionPhiladelphia : ELSEVIER;2016. 